\title{
RESEARCH ON GERMINATED WHEAT GRAIN, BROCCOLI, ALFALFA, RADISH AND HEMP SEEDS MICROBIOLOGICAL SAFETY
}

\author{
*Ilze Bernate, Martins Sabovics \\ Latvia University of Life Sciences and Technologies, Latvia \\ *Corresponding author's email: ilze.bernate@inbox.lv
}

\begin{abstract}
For a long time, germinated seeds have been used in food as a healthy product with high nutritional value and as a decor for exquisite dishes today. However, there have been many foodborne outbreaks in Europe, the United States, and other parts of the world associated with pathogens contamination of sprouts. These outbreaks pose a constant challenge to the entire sprouts industry. The aim of this study was to determine the presence of Shiga toxin-producing Escherichia coli (STEC), Salmonella spp., and potentially pathogenic bacteria in germinated grains and seeds intended for industrial food production and ready for use without further processing. In this study, grains of wheat (Triticum aestivum), seeds of broccoli (Brassica oleracea), alfalfa (Medicago sativa), radish (Raphanus sativus) and hemp (Cannabis sativa) were germinated for 72 hours and were evaluated compared with ungerminated grains and seeds. The presence of E.coli was assessed by the inoculation of enrichment broth to Tryptone Bile X-glucuronide (TBX) and Eosin methylene blue (EMB) agars, and colony characterization with MALDI-TOF. E.coli was carried out in accordance with LVS ISO 16649-2:2007. The presence of STEC was determined in accordance with ISO/TS 13136:2012. Salmonella spp. detection was in accordance with ISO 6579-1:2017. As a result, E.coli, Salmonella spp., and STEC were not found in any sample. However, environmental bacteria were detected in TBX dry seeds and 12 $\mathrm{h}$ - soaked seeds. The presence of Enterobacteriaceae was found in all samples by colony characterization on EMB by MALDI-TOF. The results show that the sprouts and edible seeds available in Latvia could be included as healthy and relatively safe food.
\end{abstract}

Key words: grains, germination, seeds, pathogenic bacteria.

\section{Introduction}

Today, consumers are particularly aware of the health problems associated with food additives. Foods "natural", "eco", "bio", processed without chemicals and preservatives are becoming more and more attractive. Sprouts have also been considered healthy food for more than 5,000 years; they are rich in nutrients, low in calories, visually alluring, and their simple production process is environmentally friendly - the qualities that are appealing to today's food consumers (Choe, Yu, \& Wang, 2018). However, warm and humid germination conditions are ideal for the growth of microorganisms (Bergspica et al., 2020). This raises food safety concerns not only about food production methods but also about how food is processed, stored, sold and consumed (Anal et al., 2020). Despite its healthy image, sprouts are one of the foods associated with foodborne outbreaks. Between 1990 and 2002, about 10\% of outbreaks in the United States were related to sprouted seeds. Several outbreaks of Salmonella spp. and Escherichia coli $\mathrm{O} 157: \mathrm{H} 7$ and O157: NM infections were observed each year. In Japan, 9451 cases of illness and 12 deaths (all children) were reported in 1996, and this attracted worldwide attention (Sikin, Zoelner, \& Rizvi, 2013). One of the main pathogens involved in germ-related outbreaks is Shiga toxin - producing E. coli (STEC). An outbreak of STEC infection in May 2011, mainly in Germany and Central Europe, claimed the lives of 54 people and was associated with fenugreek sprouts infected with an unusual $E$. coli strain O14:H4 with increased virulence and antibiotic resistance (EFSA, 2011b). To ensure the protection of public health, in 2013, the Commission established the microbiological STEC criterion for sprouts in Regulation (EU) No 209/2013. COMMISSION REGULATION (EC) No 2073/2005 of 15 November 2005 on microbiological criteria for foodstuffs (Official Journal of the European Union, 2005, L 338), which lays down the common food safety and process hygiene criteria for food in EU countries and applies to sprouts. According to it, STEC belongs to serogroups O157, O26, O111, O103, O145 and O104:H4 sprouts must not contain $25 \mathrm{~g}$ (EC) No 2073/2005). The reference analytical method is CEN/ISO TS 13136, the main step of which is based on the determination of the Shiga toxin coding genes stx1 and stx2 (EU) No 209/2013. STEC molecular diagnostic tests that the manufacturer must take to comply with the regulation and demonstrate that the manufactured product is safe for the consumer, may pay dearly. With the entry into force of the Regulation (EU) No 209/2013. Latvian sprouts producers were not able to meet all the requirements; therefore, a product manufactured in Latvia is currently not available on the Latvian market. The prevention of seed contamination is particularly important, in particular the long-term survival of pathogenic bacteria on the seed and its multiplication during the production of germinated seeds. In sprouts, contamination with microorganisms can come from the environment. One of the most important risk factors is related to the impact of agricultural practices on seed production and storage: contaminated irrigation water, manure, the presence of animals and rodents, dirty harvesting 
equipment and transport containers, and the seedling production process. There are various methods of physical and chemical treatment (rinsing or soaking in various chemical solutions or in hot water, dry heating, irradiation, hydrostatic pressure, UV light, etc.), but none of them has so far been able to provide pathogenfree seeds (EFSA, 2011). One of the physical methods used in the study is rinsing the seeds with drinking water at 12 hour intervals, and the rinsing water is visually clean.

The aim of this study was to determine the presence of Shiga toxin-producing Escherichia coli (STEC), Salmonella spp., and potentially pathogenic bacteria in germinated grains and seeds intended for industrial food production and ready for use without further processing.

\section{Materials and Methods}

Plant materials. The seeds were purchased in the local market. Broccoli (Brassica oleracea) expiration date November 2021, Lot: 62/14 and radish (Raphanus sativus) seeds expiration date July 2021, Lot: 275/A, originated in Italy in 2019, hemp (Cannabis sativa), wheat (Triticum aestivum) and alfalfa seeds were harvested in Latvia in 2019 and 2020. Seed preparation and germination were performed in the laboratory of the Faculty of Food Technology, Latvia University of Life Sciences and Technologies. Samples were packed in sterile bags and placed in a cooler bag and stored at $4 \pm 3{ }^{\circ} \mathrm{C}$ until delivered to the Institute of Food Safety, Animal Health and Environment "BIOR". Microbiological analyses were carried out at the Institute of Food Safety, Animal Health and Environment "BIOR".

\section{Samples germination}

The study was conducted in two parts. The first part was analyzed in February 2020 and the second part in November 2020. Dry grains, seeds and sprouts from each part containing 8 samples (wheat grains, seeds of broccoli, alfalfa, radish and hemp), each weighing $10 \mathrm{~g}$ and $25 \mathrm{~g}$ used for microbiological analysis, in triplicate. The second part also focused on the microbiological contamination of the product with production packaging and storage. The grains and seeds were soaked for $12 \mathrm{~h}$ and then were sprouted for 3 days ( $72 \mathrm{~h}$ ), but before that, they were washed in drinking water until the water used was visually clear. Clean grains and seeds were soaked in drinking water in a ratio of 2:1 (water:seed). The soaking was done in a polystyrene (PS) bowl for $12 \mathrm{~h}$ in the dark at 22 $\pm 2{ }^{\circ} \mathrm{C}$. After $12 \mathrm{~h}$, the seeds and grains were rinsed in drinking water until the rinsing water was visually clear. Rinsing is the main physical treatment process that separates dirt and microorganisms from seeds. Samples rinsing was performed every $12 \mathrm{~h}$ for 3 days. The rinsed seeds and grains were germinated in a glass container in room at $22 \pm 2{ }^{\circ} \mathrm{C}$, where daylight winds overnight. A day length is $8 \mathrm{~h}$ and a daylight average is $60 \pm 5 \mathrm{~lx}$. Darkness lasts $16 \mathrm{~h}$ at $0 \mathrm{~lx}$. Germinated hemp sprouts were not used in further studies because they did not show good properties - they are visually fresh, crunchy with a good taste according to hemp but when eating the sprouts, the bark is hard and difficult to chew.

Samples storage

After 3 days of germination, the sprouts were rinsed with drinking water until the water was visually clean and packaged in closed polypropylene $300 \mathrm{ml}$ containers. Wheat sprouts $100 \mathrm{~g}$, alfalfa sprouts 50 $\mathrm{g}$, broccoli and radish sprouts $75 \mathrm{~g}$ were packaged. Packaged sprouts were stored for 8 days in a cold chamber at $3 \pm 2{ }^{\circ} \mathrm{C}$ in the dark, from which $10 \mathrm{~g}$ and $25 \mathrm{~g}$ were taken for microbiological analysis.

Microbiological analyses

Microbiological analyses were performed for all dried seeds and wheat grains, soaked and sprouted wheat grains, broccoli, radish and alfalfa seeds, the test was also carried out after sprouting and after 5 and 8 days of storage. From each sample 25 g STEC and Salmonella spp. and $10 \mathrm{~g}$ E.coli and Enerobacreriaceae spp were taken.

Enerobacreriaceae spp. determination with Violet red bile glucose

Sample of Enerobacreriaceae spp the decimal dilutions preparation has been performed in accordance with the standard LVS EN ISO 6887-1. Dry grains and seeds were tested as controls. Each sample portion was performed in triplicate. $10 \pm 0.02 \mathrm{~g}$ of the sample per replicate was weighed in sterile filter bags and 90 $\mathrm{ml}$ of MRD (maximum recovery diluent) was added. The sample was processed in a Stomacher ${ }^{\circledR}$ blender at $230 \mathrm{rpm}$ for $30 \mathrm{s.} 1 \mathrm{ml}$ of the sample and $1 \mathrm{ml}$ of the $10 \times \mathrm{MRD}$ diluted sample into a sterile Petri dish was brought. $15 \mathrm{ml}$ of VRBG (Violet red bile glucose) medium, mix thoroughly was added and the medium was allowed to solidify. It was incubated at $37^{\circ} \mathrm{C}$ for 18-24 h.

STEC and Salmonella spp. detection by real-time PCR

DNA was isolated from $1 \mathrm{ml}$ of enrichment medium with InstaGene TMMatrix reagent for STEC and mericon TMDNA Bacteria reagent for Salmonella spp. investigation. The presence of STEC in the sample was determined in accordance with ISO/TS 13136 by real-time PCR (polymerase chain reaction) by determining the presence of stx 1 and stx 2 genes in the enriched sample. The presence of genetic material in the sample was determined with a set of mericon ${ }^{\circledR}$ Pathogen Detection reagents.

Detection of E.coli in enrichment medium

The analysis was carried out by weighing $25 \pm$ $0.02 \mathrm{~g}$ of the sample in triplicate, placed in sterile filter bags and added $225 \mathrm{ml}$ of BPW (buffered peptone 
water). The sample was processed in a Stomacher ${ }^{\circledR}$ blender at $230 \mathrm{rpm}$ for $30 \mathrm{~s}$ and incubated at $37{ }^{\circ} \mathrm{C}$ for 18-24 h. Samples were seeded on TBX and EMB medium and incubated at $44^{\circ} \mathrm{C}$ and $37{ }^{\circ} \mathrm{C}$ for $24 \mathrm{~h}$, respectively. The species affiliation of the grown colonies was determined by MALDI-TOF (matrixassisted laser desorption and ionization time-offlight) mass spectrometry using the MALDI Compass BioTyper Tм 3 database (Bruker Daltonics).

Identification of bacteria with matrix laser desorption and ionization flight time mass spectrometry

Colonies typical of Enterobacteriaceae were frequently observed, and these bacteria were identified. The random colonies were transferred to a Nutrient agar (NA) plate and analyzed by matrixassisted laser desorption and ionization time-of-flight (MALDI-TOF) mass spectrometry using the MALDI Compass BioTyper TM 3 database (Bruker Daltonics). Microbiological analyses were performed for the water used for rinsing and soaking, in accordance with the methods for determining safety and quality indicators LVS EN ISO 9308-1, LVS EN ISO 9308-2, LVS EN ISO 7899-2, LVS EN ISO 6222.

Statistical analyses

Data were analyzed using RStudio, mean and standard deviations were calculated for listed bacterial populations (log CFU per gram). An Anova analysis was used to determine whether there were a significant difference between ungerminated seeds contamination with Enterobacteriaceae and germinated seeds with a confidence level $(\mathrm{P}<0.05)$.

\section{Results and Discussion}

The target E.coli, Salmonella spp., and STEC were not found in any samples, but Enterobacteriaceae was found in both seeds and sprouts. Enterobacteriaceae is known to be conditional food pathogens occurring in the human and animal intestinal tract but generally not associated with outbreaks of food-borne infections, including Citrobacter braakii and Cronobacter sakazakii (Iversen \& Forsythe, 2004; Bergspica et al., 2020). The predominant species, determined by MALDI-TOF mass spectrometry, were Enterococcus faecium (29\%) and Enterobacter cloacae (46\%). Pantoea agglomerans (9\%) was detected in dry hemp seeds. Pantoea calida (4\%), Lelliottia amnigena (4\%), Klebsiella oxytoca (4\%) were found in soaked wheat and Enterobacter hermannii (4\%) in broccoli sprouts. The percentage of Enterobacteriaceae species detected in first part is shown in Figure 1.

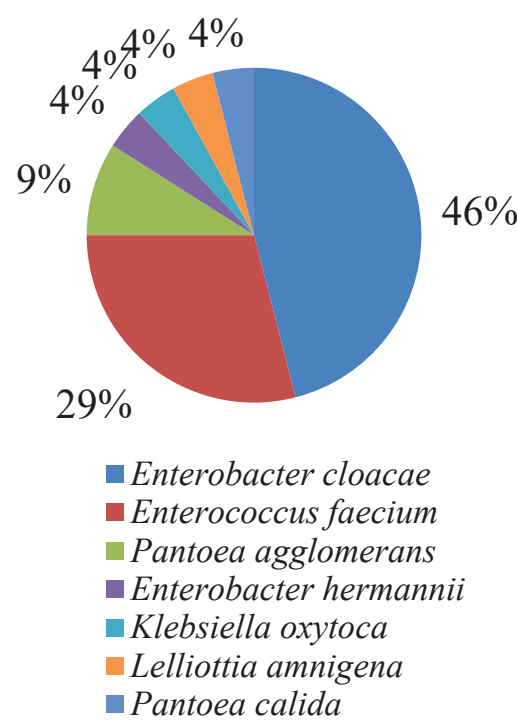

Figure 1. Species of Enterobacteriaceae detected in first part.

This study revealed that, similarly to the first part, Salmonella spp., E.coli and STEC were not detected, but Enterobacteriaceae characteristic of soil and environmental bacteria were detected, similar to several Enterobacteriaceae species isolated in previous studies, such as Enterobacter cloacae, Pantoea calida, Cronobacter sakazakii from sprouts, salads, herbs, spices, and products ready to eat vegetables (Iversen \& Forsythe, 2004) as well as described (Bergspica et al., 2020). In dry seeds and grains, the number of Enterobacteriaceae increased from $<1 \mathrm{log}$ $\mathrm{CFU} \mathrm{g} \mathrm{g}^{-1}$ to $2.0 \log \mathrm{CFU} \mathrm{g}^{-1}$ in wheat grain un radish seeds increased on average to $3.3 \log \mathrm{CFU} \mathrm{g}^{-1}$. After 3 days of germination, more than $>6.0 \log \mathrm{CFU} \mathrm{g^{-1 }}$ have already been detected for all germinated seed types. During the next 5 days of storage, up to $8.0 \log \mathrm{CFU} \mathrm{g}^{-1}$ were reached in most samples with

Results of Enterobacteriaceae spp. $\log \mathrm{CFUg}^{-1}$

\begin{tabular}{|l|c|c|c|c|c|}
\hline \multicolumn{1}{|c|}{ Seeds } & dry & soaked & sprouts & stored for 5 days & stored for 8 days \\
\hline Broccoli & 0.00 & 1.30 & $>6.00$ & 7.49 & 7.36 \\
\hline Wheat & 2.00 & 3.23 & $>6.00$ & 7.59 & 7.28 \\
\hline Alfalfa & 0.00 & 3.18 & $>6.00$ & 8.13 & 7.78 \\
\hline Radish & 3.23 & 4.33 & $>6.00$ & 7.29 & 7.27 \\
\hline Hemp & 0.00 & 3.30 & $>6.00$ & Not tested & Not tested \\
\hline
\end{tabular}


no significant increase at $(\mathrm{P}<0.05)$ in population on the day 8 . The data obtained are similar to previous studies on alfalfa sprouts after $48 \mathrm{~h}$ of storage Enterorobacteriaceae increased on average from $6.7 \log \mathrm{CFU} \mathrm{g}{ }^{-1}$ to $8.0 \log \mathrm{CFU} \mathrm{g} \mathrm{g}^{-1}$ and listed Enterobacteriaceae averaged $6.0 \log \mathrm{CFU} \mathrm{g}^{-1}$ in ripe vegetables under storage conditions $\left(6^{\circ} \mathrm{C}\right.$ for 72 hours $)$ (Rotundo et al., 2019). In second part, in samples, colonies of Enterobacteriaceae, similar to those in first part samples, Enterobacter cloacae was found in dry radish seeds, Enterococcus faecium - broccoli, hemp seed and wheat, while Pantoea agglomerans - alfalfa seeds. Pantoea calida, Lelliottia amnigena, Klebsiella oxytoca and Enterobacter cloacae were found in soaked wheat. Broccoli, radish and wheat sprouts Enterobacter cloacae, broccoli sprouts Enterobacter hermannii, radish sprouts Klebsiella variicola, but Cronobacter sakazakii were found in wheat and alfalfa sprouts. The percentage of Enterobacteriaceae colonies species is shown in Figure 2.

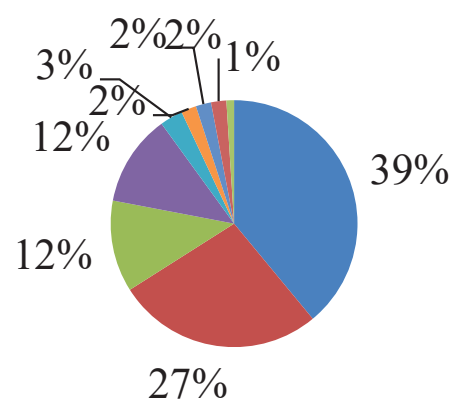

$\begin{array}{ll}\square \text { Enterobacter cloacae } & \text { Cronobacter sakazakii } \\ \square \text { Klebsiella variicola } & \text { Enterococcus faecium } \\ \square \text { Pantoea agglomerans } & \text { Enterobacter hermannii } \\ \square \text { Klebsiella oxytoca } & \text { Lelliottia amnigena } \\ \square \text { Pantoea calida } & \end{array}$

Figure 2. Species of Enterobacteriaceae colonies detected in second part.

Sprouts production is usually an intensive process using water to wash away dirt, pathogens and other substances from production, harvesting, storage and transport before soaking the seeds. During germination, the sprouts are rinsed every 12 hours to neutralize the heat released from seed germination (average temperature rises from $34^{\circ} \mathrm{C}$ to $36{ }^{\circ} \mathrm{C}$ ) and to prevent drying. Therefore, water quality can have a direct impact on the potential for pollution. In our study, the water used for rinsing and soaking was subjected to microbiological analyses in accordance with the methods for determining safety and quality indicators. The results correspond to the drinking water specified in the regulatory enactments Regulations of the Cabinet of Ministers of the Republic of Latvia No. $671 / 2017$. In the early germination stage, germinated seeds provide nutrients to microorganisms. (Sikin et al., 2013; Kim et al., 2013; Koizumi et al., 2008). These nutrients include low molecular weight metabolites consisting of carbohydrates, amino acids, flavonoids, sterols, and minerals that provide essential nutrients for bacterial cell growth (Cui et al., 2018; Nelson, 1990; Schiltz et al., 2015). The number of Enterobacteriaceae in sprouts was relatively high, but it is not used to indicate the microbiological quality of fresh fruits, vegetables and sprouts (Abadias et al., 2008). Despite the large number of bacteria, these products showed no signs of spoilage. Sprouts are recognized as a relatively dangerous food, having the growth potential of pathogens in the germination process, as there is no specific step in the production process to reduce or destroy pathogens presented in untreated sprouts (NACMCF, 1999). High levels of micro-organisms do not necessarily pose public health problems. The presence and growth of pathogenic microorganisms is a concern. In the case of our analysed sprouts, it is recommended to wash the products before eating. However, high level of non-pathogenic micro-organisms in sprouts cannot be prevented or reduced by simple washing (MohleBoetani et al., 2001). The obtained results coincide with similar studies found in the literature (Abadias et al., 2008; Gabriel et al., 2007; Martínez-Villaluenga et al., 2008; Baenas et al., 2017). Sprouts could be considered as relatively safe fresh products in terms of their microbiological contamination, as even after prolonged storage in a cold store, no pathogenic bacteria (Shiga toxin-producing Escherichia coli (STEC), Salmonella spp) were found. Cronobacter spp of Enterobacteriaceae family are new food-borne pathogen. Foods contaminated with Cronobacter spp. may pose a risk to infants or immunocompromised adults (Berthold-Pluta et al., 2017). Cronobacter spp. are environmental bacteria and are found in water and soil, as well as in various foods, including dairy, meat, rice and other cereals, vegetables. In addition, Cronobacter spp. are often isolated from lettuce and vegetable salads (Berthold-Pluta et al., 2017; Chenu \& Cox, 2009; Iversen \& Forsythe, 2003). The data of the study showed microbiological contamination of seeds and sprouted seeds, but do not indicate microbiological quality, because there are no binding standards in Latvia and Europe of Enterobacteriaceae for this type products.

\section{Conclusions}

The study showed that E.coli, STEC, Salmonella spp. were not detected in all types of seeds, grains and sprouts, but Enterobacteriaceae were detected in all samples. The highest microbiological contamination was observed in germinated seeds after three days of germination and during the next 5 days of storage in the range of $7.0 \log \mathrm{CFU} \mathrm{g}^{-1}$ to $8.13 \log \mathrm{CFU} \mathrm{g} \mathrm{g}^{-1}$ and 
no increase in microbiological contamination was observed in the following days of storage. The lowest Enterobacteriaceae spp. count of $<10 \log$ CFU g ${ }^{-1}$ was observed in dry seeds and soaked seeds increased from $10 \mathrm{CFU} g$ to $3.0 \log \mathrm{CFU} \mathrm{g}^{-1}$.

Among the bacteria of the species: Enterobacteriaceae, Cronobacter sakazakii, Klebsiella variicola, Enterobacter cloacae, Klebsiella oxytoca, Enterococcus faecium, Lelliottia amnigena, Pantoea calida, Pantoea agglomerans were identified, indicating that these products may be dangerous especially for children and people with low immunity. This indicates that the seeds and grains used were contaminated with the micro-organisms found during primary production, as the germination process was in accordance with the requirements of good hygiene and good production and the water used was in accordance with drinking water.

\section{Acknowledgements}

This research was supported by the Latvia University of Life Sciences and Technologies project 'Strengthening Research Capacity in the Latvia University of Life Sciences and Technologies'. Project No. 3.2-10/121.

The authors would like to thank Aija Jerina and Alla Cibrovska for assistance, shared knowledge and experience during the microbiological experiments.

\section{References}

Abadias, M., Usall, J., Anguera, M., Solsona, C., \& Viñas, I. (2008). Microbiological quality of fresh, minimallyprocessed fruit and vegetables, and sprouts from retail establishments. International Journal of Food Microbiology, 123(1-2), 121-129. DOI: 10.1016/j.ijfoodmicro.2007.12.013.

Anal, A.K., Perpetuini, G., Petchkongkaew, A., Tan, R., Avallone, S., Tofalo, R., ... Waché, Y. (2020). Food safety risks in traditional fermented food from South-East Asia. Food Control, 109, 106922. DOI: 10.1016/j.foodcont.2019.106922.

Baenas, N., Gómez-Jodar, I., Moreno, D.A., García-Viguera, C., \& Periago, P.M. (2017). Broccoli and radish sprouts are safe and rich in bioactive phytochemicals. Postharvest Biology and Technology, 127, 60-67. DOI: 10.1016/j.postharvbio.2017.01.010.

Bergspica, I., Ozola, A., Miltina, E., Alksne, L., Meistere, I., Cibrovska, A., \& Grantiņa-Ievina, L. (2020). Occurrence of Pathogenic and Potentially Pathogenic Bacteria in Microgreens, Sprouts, and Sprouted Seeds on Retail Market in Riga, Latvia. Foodborne Pathogens and Disease, 17(7), 420-428. DOI: 10.1089/ fpd.2019.2733.

Berthold-Pluta, A., Garbowska, M., Stefańska, I., \& Pluta, A. (2017). Microbiological quality of selected readyto-eat leaf vegetables, sprouts and non-pasteurized fresh fruit-vegetable juices including the presence of Cronobacter spp. Food Microbiology, 65, 221-230. DOI: 10.1016/j.fm.2017.03.005.

Chenu, J.W., \& Cox, J.M. (2009). Cronobacter ('Enterobacter sakazakii'): current status and future prospects. 49, 153-159. DOI: 10.1111/j.1472-765X.2009.02651.x.

Choe, U., Yu, L.L., \& Wang, T.T.Y. (2018). The science behind microgreens as an exciting new food for the $21^{\text {st }}$ century. J Agric Food Chem; 66: 11519-11530.

COMMISSION REGULATION (EC) No 2073/2005 of 15 November 2005 on microbiological criteria for foodstuffs.

COMMISSION REGULATION (EU) No 209/2013 of 11 March 2013 amending Regulation (EC) No 2073/2005 as regards microbiological criteria for sprouts and the sampling rules for poultry carcases and fresh poultry meat.

Cui, Y., Liu, D., \& Chen, J. (2018). Fate of various Salmonella enterica and enterohemorrhagic Escherichia coli cells attached to alfalfa, fenugreek, lettuce, and tomato seeds during germination. Food Control, 88, 229-235. DOI: 10.1016/j.foodcont.2018.01.011.

[EFSA] European Food Safety A uthority. Shiga toxin-producing E. coli (STEC) O104:H4 2011 outbreaks in Europe: Taking stock. EFSA J 2011a; 9:2390.

EFSA Panel on Biological Hazards (BIOHAZ). Scientific Opinion on the risk posed by Shiga toxin-producing Escherichia coli (STEC) and other pathogenic bacteria in seeds and sprouted seeds. EFSA J 2011; 9:2424.

Gabriel, A.A., Berja, M.C., Estrada, A.M.P., Lopez, M.G.A.A., Nery, J.G.B., \& Villaflor, E.J.B. (2007). Microbiology of retail mung bean sprouts vended in public markets of National Capital Region, Philippines. Food Control 18 (10), 1307-1313.

Iversen, C., \& Forsythe, S. (2003). Risk profile for Enterobacter sakazakii, an emergent pathogen associated with infant milk formula. Trends Food Sci. Technol. 14,443e454.

Iversen, C., \& Forsythe, S. (2004). Isolation of Enterobacter sakazakii and other Enterobacteriaceae from powdered infant formula milk and related products. Food Microbiology, 21(6), 771-777. DOI: 10.1016/j. fm.2004.01.009. 
Kim, S.A., Kim, O.M., \& Rhee, M.S. (2013). Changes in microbial contamination levels and prevalence of foodborne pathogens in alfalfa (Medicago sativa) and rapeseed (Brassica napus) during sprout production in manufacturing plants. Letters in Applied Microbiology, 56(1), 30-36. DOI: 10.1111/lam.12009.

Koizumi, M., Kikuchi, K., Isobe, S., Ishida, N., Naito, S., \& Kano, H. (2008). Role of seed coat in imbibing soybean seeds observed by micro-magnetic resonance imaging. Annals of Botany, 102(3), 343-352. DOI: 10.1093/aob/mcn095.

Martínez-Villaluenga, C., Frías, J., Gulewicz, P., Gulewicz, K., \& Vidal-Valverde, C. (2008). Food safety evaluation of broccoli and radish sprouts. Food Chem. Toxicol. 46 (5), 1635-1644.

Mohle-Boetani, J.C., Farrar, J.A., Werner, S.B., Minassian, D., Bryant, R., Abbott, S., Slutsker, L., \& Vugia, D.J. (2001). Escherichia coli O157 and Salmonella infections associated with sprouts in California, 19961998. Ann. Intern. Med. 135 (4), 239-247.

NACMFC (National Advisory Committee on Microbiological Criteria for Food) (1999). Microbiological safety evaluations and recommendation on sprouted seeds. URL: Retrieved February 22, 2021, from http:// vm.cfsan.fda.gov/ mow/sprouts2.html.

Nelson, E.B. (1990). Exudate molecules initiating fungal responses to seeds and roots. Plant and Soil, 129(1), 61-73. DOI: 10.1007/BF00011692.

Rotundo, L., Amagliani, G., Carloni, E., Omiccioli, E., Magnani, M., \& Paoli, G. (2019). Evaluation of PCR-based methods for the identification of enteroaggregative hemorrhagic Escherichia coli in sprouts. International Journal of Food Microbiology, 291(August 2018), 59-64. DOI: 10.1016/j.ijfoodmicro.2018.11.011.

Schiltz, S., Gaillard, I., Pawlicki-Jullian, N., Thiombiano, B., Mesnard, F., \& Gontier, E. (2015). A review: What is the spermosphere and how can it be studied? Journal of Applied Microbiology, 119(6), 1467-1481. DOI: $10.1111 /$ jam.12946.

Sikin, A.M., Zoellner, C., \& Rizvi, S.S. (2013). Current intervention strategies for the microbial safety of sprouts. Journal of Food Protection, 76(12), 2099-2123. DOI: 10.4315/0362-028X.JFP-12-437. 